\title{
An investigation on the effects of the profit quality structures on Iranian Co. capital cost
}

\author{
Hassan Ghodrati ${ }^{\mathrm{a}}$, Seyed Reza Ghazi Fini ${ }^{\mathbf{b}^{*}}$ and Kashaninezhad Abyaneh Mustafa ${ }^{\mathrm{a}}$
}

${ }^{a}$ Department of Accounting \& Management, Kashan Branch, Islamic Azad University, Kashan, Iran

${ }^{b}$ MA in Accounting of Kohgiloye and Boyerahmad Science and Research Branch, Islamic Azad University, Iran

\begin{tabular}{|c|c|}
\hline C H R O N I C L E & A B S TRACT \\
\hline $\begin{array}{l}\text { Article history: } \\
\text { Received February 15, } 2013 \\
\text { Received in revised format } \\
3 \text { May } 2013 \\
\text { Accepted May } 42013 \\
\text { Available online } \\
\text { May } 62013 \\
\text { Keywords: } \\
\text { Earnings quality structures } \\
\text { Earnings persistence } \\
\text { Earnings predictability } \\
\text { Cost of equity }\end{array}$ & $\begin{array}{l}\text { This paper evaluates the effect of profit quality structures on capital cost and the primary } \\
\text { objective is to disclose the effect to investors. The research methodology is practical based on } \\
\text { its goal and its research design is Expose-Facto. The study selects } 36 \text { Iranian firms as statistical } \\
\text { sample over the period 2006-2010 from some Iranian firms and the study selects post } \\
\text { performances from their financial reports. The statistical parameters, statistical plots, multiple- } \\
\text { variables linear-regression and correlation analysis are implemented for data analysis. The } \\
\text { results show that the estimated model could explain } 22 \text { percentages of variable changes. This } \\
\text { means that there is a weak linear relationship between cost of capital and profit persistence, } \\
\text { profit predictability and other variables. Based on the regression estimation we concluded that } \\
\text { there was a direct relationship between earnings persistence and cost of capital and there was a } \\
\text { reverse relationship between earnings predictability and cost of capital. }\end{array}$ \\
\hline
\end{tabular}

\section{Introduction}

During the past few years, we have witnessed a number of corporate scandals created the public perception that accounting information provided in a corporate culture fixated on stock price performance could not be trusted. While media attention has concentrated on a few high-profile cases of fraudulent accounting schemes, e.g., at Enron and WorldCom, recent empirical studies imply that the practice of earnings management is prevalent among publicly traded firms. The findings show that firms manage earnings to influence stock market perceptions, to increase management's compensation, to reduce the likelihood of violating lending agreements, and to prevent regulatory intervention. In this paper, we perform an investigation on the role of earnings management in affecting a firms' cost of capital. Given the relative importance of a firm's cost of capital for a variety of corporate decisions, from determining the hurdle rate for investment projects to influencing the composition of the firm's capital structure, it is surprising that the link between cost of capital and earnings management has received little attention. To date, the theoretical literature has primarily

*Corresponding author.

E-mail addresses: sr.ghazi@yahoo.com (S. R. Ghazi Fini) 
concentrated on detecting circumstances in which earnings manipulation emerges in a single firm setting. While this literature has provided many useful insights, its applicability to cost of capital issues is limited. In a single-firm setting, firm-specific risk is priced, because there are no alternative securities, which could permit investors to diversify away idiosyncratic risk. It is unclear, however, to what extent accounting information could reduce non-diversifiable risks in a multi-asset economy.

In this paper, we take up this task, and present a simple but rigorous model of earnings manipulation with multiple firms whose cash flows are correlated. Important features of our model are risk adverse investors, myopic managers, and resource costs of manipulation. Managers are concerned more on short-term stock prices because of their compensation contract. The increasingly and rapid changes on economic relationship could lead to higher competition for commercial and industrial activities. All of firms need to on-time and suitable investment for their survival and these firms prepare financial reports for their purposes. One of the most important parameters on these reports is accounting profit. The investors and other user financial report users have pay special attention for profit quality. Experimental effects of profit are implemented instead of profit quality. Schipper and Vincent (2003) considered four criteria for profit quality evaluation including profit trend, relationship between profit and liquidity, quality profit specifications and decision-making.

Francis at el. (2004) introduced two categories for profit quality including accounting and market criteria. The "Profit quality" is a useful criterion for decision-making and it is profit used with decision-maker from financial reports. This profit influences on the investor risk and has a reverse relationship with cost of capital. As profit quality increases, the uncertainty to profit decreases and investor risk rate decreases too. In this paper, we evaluated the relation between profit quality structure with cost of capital or minimum of the investor rate of return. We evaluated "earnings persistence” and "earnings predictability” as Profit Quality stricture elements.

Bellovary at el. (2005) reported that profit quality could be described with one of four criteria including profit trend, relationship between liquid and commitment profit, conceptual specifications and decision-making criteria. Frankel at el. (2009) evaluated relationship between predictability of past profits with shares return and profit sustainability and reported that the profit changes could not predict shares returns. Ghadiri Moghaddam (2011) studied earning components information content and earning persistence. Jeon et al. (2004) studied the relationship between persistence of abnormal earnings and usefulness of accounting information in hotel companies.

\section{Research hypotheses}

The proposed study of this paper considers the following main hypotheses,

Main hypothesis: There is a relationship between earning quality structure with cost of capital.

The main hypothesis of this paper is divided into the following sub-hypotheses

1) There is a relationship between earning persistence with cost of capital.

2) There is a relationship between earning predictability with cost of capital.

\section{Research methodology}

The research methodology is practical based on its goal and its research design is Expose-Facto. The study selects 36 Iranian firms as statistical sample over the period 2006-2010 from some Iranian firms and the study selects post performances from their financial reports. The statistical parameters, statistical plots, multiple-variables linear-regression and correlation analysis are implemented for data analysis. We use descriptive methods such as statistical parameters computation. The multi variables 
linear-regression has been used for variables relation estimation. The statistical analysis was performed with SPSS17 \& Rviews7 packages. Our research model generally formulated as follows:

$y=f\left(x_{1}, x_{2}, x_{3}, x_{4}, x_{5}\right)$

where $\mathrm{x}_{1}=$ persistence, $\mathrm{x}_{2}=$ Predictability, $\mathrm{x}_{3}=$ firms size, $\mathrm{x}_{4}=\mathrm{BM}$ and $\mathrm{x}_{5}=$ Beta. This relationship is estimated with multi-variables linear- regression as follows:

$Y=a_{0}+\beta_{1} x_{1}+\beta_{2} x_{2}+\beta_{3} x_{3}+\beta_{4} x_{4}+\beta_{5} x_{5}$

The dependent variable (y) in this relationship is the cost of capital, which is computed as follows,

$\mathrm{y}=\mathrm{r}_{\mathrm{PEG}}=\sqrt{\frac{\mathrm{eps}_{2}-\mathrm{eps}_{1}}{\mathrm{p}_{0}}}$

where eps $_{1}$ is the next -year earns per share, eps ${ }_{2}$ is the second consecutive year's earn per share and $\mathrm{p}_{0}$ is current stock price. Earning persistence is computed as follows,

$\mathrm{x}_{\mathrm{j}, \mathrm{t}}=\emptyset_{0, \mathrm{j}}+\emptyset_{1, \mathrm{j}} \mathrm{x}_{\mathrm{j}, \mathrm{t}-1}+\mathrm{V}_{\mathrm{j}, \mathrm{t}}$

where $\emptyset_{1, \mathrm{j}}$ is estimated correlation estimated, $\mathrm{x}_{\mathrm{j}, \mathrm{t}}$ is current year earn before abnormal items to shares number and persistence equals $-\emptyset_{1, \mathrm{j}}$. Earning predictability is computed as follows,

$\mathrm{x}_{\mathrm{j}, \mathrm{t}}=\emptyset_{0, \mathrm{j}}+\emptyset_{1, \mathrm{j}} \mathrm{x}_{\mathrm{j}, \mathrm{t}-1}+\mathrm{V}_{\mathrm{j}, \mathrm{t}}$

where earning predictability is $\sqrt{\partial^{2}\left(V_{j}\right)}$. The firm size is firm value logarithm; Beta is computed Beta with Rahavard package and BM is log of firm s book-to-market value ratio.

\section{Findings}

As mentioned earlier, we gathered data about our statistical community in this section summarized research results. On the first descriptive results about research variables was described. On the second the pre-assumptions research hypothesis were evaluated. Finally, the relationship between variables were measured.

\subsection{Descriptive results}

Table 1 demonstrates some basic statistics on data.

\section{Table 1}

Variables Descriptions

\begin{tabular}{llllllll}
\hline Variables & Minimum & Maximum & Average & Medium & Std. Deviation & Skewkness & Kurtosis \\
\hline Cost of Capital & 0 & 1267.09 & 299.6 & 259.3 & 212.54 & 1.351 & 2.803 \\
Adjust Cost of Capital & 3.24 & 7.14 & 5.27 & 5.6 & 0.70 & -0.443 & 0.231 \\
Earning Persistence & 0.03 & 1.74 & 0.75 & 0.80 & 0.65 & 0.297 & 0.369 \\
Earning Predictability & 91.832 & 1654.43 & 1217.6 & 1165.5 & 338.98 & 0.231 & -1.514 \\
Size & 24.03 & 30.62 & 26.47 & 26.2 & 1.36 & 0.617 & -0.195 \\
Book Value to Market value & -9.55 & 0.93 & -0.97 & -0.76 & 1.6 & -3.326 & 14.384 \\
Beta & -26.3 & 95.45 & 1.44 & 0.18 & 8.85 & 8.530 & 91.132 \\
\hline
\end{tabular}


As we can observe from the results of Table 1, there are seven research variables including cost of capital, adjusted cost of capital, earning persistence, earning predictability, size, book value to market value and Beta. The cost of capital was at least 0 and the average and maximum were 299.6 and 1267, respectively. These parameters for adjusted cost of capital are 1.48, 5.27and 7.14. Minimum, average and maximum earning persistence are $0.03,0.75$ and 1.74 , respectively.

Minimum, average and maximum of earning predictability are 91.832, 1217.6 and 1654.43, respectively. Minimum, average and maximum of size are 24.03, 26.47 and 30.62, respectively. Minimum, average and maximum of Book Value to Market value are -9.55,-0.97 and 0.93, respectively. Minimum, average and maximum of Beta are -26.3, 1.44 and 95.45, respectively. As we said before this research, method is descriptive. Therefore, we evaluated model pre-assumption with descriptive statistical methods.

\subsection{Normality test for variables}

We have used skewness and kurtosis standard coefficients given in Table 1 for normality test. These coefficients were 1.351 and 2.808, respectively and for cost of capital variable, that there were greater than 0.1 , which means this variable is not normally distributed. We substituted these variables with logarithm quantities. The skewness and kurtosis coefficient are -0.444 and 0.231 , respectively and this means that dependent variable is normally distributed.

\subsection{Normality test for residuals}

The next is to test whether regression estimation of residuals is normally distributed or not. The residuals are the differences between actual and estimated values of dependent variables. Table 2 demonstrates details of statistics associated with residuals.

\section{Table 2}

Residuals parameters

\begin{tabular}{lccccl}
\hline Number & Average & Medium & Standard Deviation & Skewers & Kurtosis \\
\hline 104 & 0 & 0.14 & 0.64 & -0.576 & 0.476 \\
\hline
\end{tabular}

As we observe from the results of Table 2, the skewness and kurtosis standard coefficients are 0.0576 and 0.0476 , respectively and they are less than 0.1 . Therefore, we can conclude that residuals are normally distributed.

\subsection{Stability of variance}

The third pre-assumption of multi-variable Linear-regression is variance stability. For this reason, we evaluated residuals plot and realized that there was not any certain trend and, therefore, variance stability has been accepted.

\subsection{Linear in-dependency variables}

We have evaluated linear independency variables with correlation analysis. As we showed on Table3, the correlation coefficient among independent variables is near to zero, then these variable have linear independency. We have summarized linear in-dependency analysis on Table 3. As we can see from the results of Table 3, all of correlations coefficients are near to zero, therefore, linear independency variables is accepted. 
Table 3

Linear Independency Variables

\begin{tabular}{lccccc}
\hline & $\begin{array}{c}\text { Earning } \\
\text { Persistence }\end{array}$ & $\begin{array}{c}\text { Earning } \\
\text { Predictability }\end{array}$ & Size & BM & Beta \\
\hline Earning Persistence & 1 & 0.000 & -0.044 & -0.80 & 0.129 \\
Earning Predictability & 0.000 & 1 & 0.011 & -0.70 & -0.133 \\
Size & -0.044 & 0.011 & 1 & -0.153 & -0.101 \\
BM & -0.080 & -0.070 & -0.153 & 1 & 0.70 \\
Beta & 0.129 & -0.133 & -0.101 & 0.70 & 1 \\
\hline
\end{tabular}

\subsection{Variables relationship Analysis}

As we showed the based on previous section analysis all of the multi-variables linear-regression are established. Then we used multi-variables linear-regression for variables relation analysis. The regression estimation was summarized on Table 4 as follows,

\section{Table 4}

Regression Estimation

\begin{tabular}{lcc}
\hline variable & Beta & Error \\
\hline constant & 12.21878 & 1.337141 \\
Earning Persistence & 0.132459 & 0.100227 \\
Earning Predictability & -0.000147 & 0.000198 \\
Size & -0.245076 & 0.049460 \\
BM & -0.007310 & 0.39953 \\
Beta & -0.006131 & 0.006661 \\
\hline
\end{tabular}

Table 4 summarizes the results of regression analysis and the results are summarized as follows,

$Y=12.21878+0.132459$ Persistence - 0.000147 Predict - 0.245076 Size - 0.007310BM $0.006131 B e t a$

Our results show that the determination coefficient is 0.219 and then the linear relation between variables is low, because the determination coefficient is near zero. If we delete the constant from regression equation and analyze other parameters regression, relationship among all variables can be summarized in Table 5 as follows,

\section{Table 5}

Variable Relation Type

\begin{tabular}{lll}
\hline Variable & Coefficient & Relation Type \\
\hline Earning Persistence & 0.132459 & Direct \\
Earning Predictability & -0.000147 & Inverse \\
Size & -0.245076 & Inverse \\
BM & -0.007310 & Inverse \\
Beta & -0.006131 & Inverse \\
\hline
\end{tabular}

As we can observe from the results of Table 5, except profit stability, other variables have inversed relationship with dependent variable or cost of capital.

\section{Conclusion}

As we have already stated, our research method was descriptive and we studied all statistical community. We used multi-variable linear- regression for variables relationship evaluation. Our results showed that the estimated model could explain 22 percentage of variable changes because 
determination coefficient was 0.219 . This means that there was a weak linear relationship between cost of capital and profit persistence, profit predictability and other variables. In summary, we have

1. There is a direct relationship between cost of capital and profit persistence.

2. There is an inverse relationship between cost of capital and profit predictability, market to book value, size and Beta.

Our results are consistent with Fransis at el. (2004) where they found that there was an inverse relationship between profit quality and cost of capital. In addition, Ghorban at el. (2011) found that there was an inverse relationship between cost of capital with profit predictability and stability. Bolo (2007), Bolo at el. (2009) found that there is a direct relation between profit stability and cost of capital. Tayefe (2007) found that there was an inverse relationship between predictability with cost of capital and finally another research results indicated that there was a reverse relationship between predictability and cost of capital.

\section{References}

Bellovary, J. L., Giacomino, D. E., \& Akers, M. D. (2005). Earnings quality: It's time to measure and report. Accounting Faculty Research and Publications, 11, 32-27.

Bolo, Gh., \& Saghafi, A. (2009). Cost of Equity \& Earning Specifications. Accounting Researches, 2, 4-27.

Bolo, Gh. (2007). Cost of equity \& earning specifications. un-published doctoral thesis, Allameh Tabatabee University.

Francis, J., LaFond, R., Olsson, P. M., \& Schipper, K. (2004). Costs of equity and earnings attributes. The Accounting Review, 79(4), 967-1010.

Francis, J., LaFond, R., Olsson, P., \& Schipper, K. (2005). The market pricing of accruals quality. Journal of Accounting and Economics, 39(2), 295-327.

Frankel, R., \& Litov, L. (2009). Earnings persistence. Journal of Accounting and Economics, 47(1), 182-190.

Ghadiri Moghaddam, A. (2011). Earning components information content and earning persistence. Accounting Researches, 10, 98-118.

Jeon, S., Kang, I., \& Lee, S. (2004). The relationship between persistence of abnormal earnings and usefulness of accounting information in hotel companies. Tourism management, 25(6), 735-740.

Oei, R., Ramsay, A., \& Mather, P. (2008). Earnings persistence, accruals and managerial share ownership. Accounting \& Finance, 48(3), 475-502.

Osmani M.G. (2003). Cost of Capital Model and its Influential Factors. un-published doctoral thesis, Allameh Tabatabee University, Tehran, Iran.

Schipper, K., \& Vincent, L. (2003). Earnings quality. Accounting horizons, 17, 97-110. 